
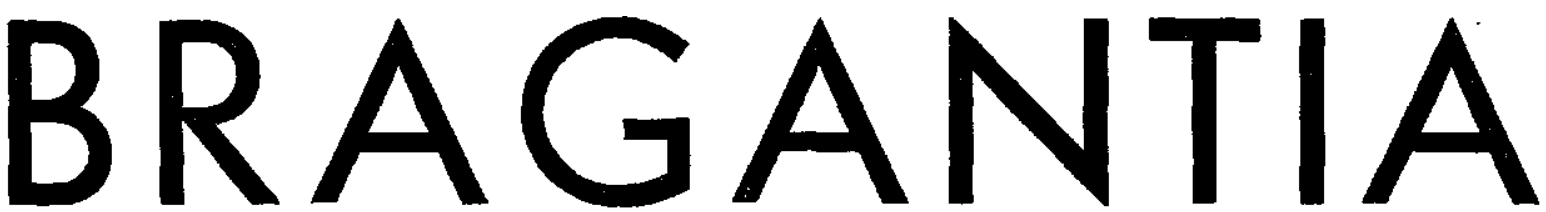

Boletim Técnico do Instituto Agronômico do Estado de São Paulo

Vol. 16

Cámpinas, dezenbro de 1957

N. ${ }^{\circ} 19$

\title{
DETERMINAÇÃO DO PERÍODO DE TEMPO PARA AMONIFICAÇÃO E NITRIFICAÇÃO DE DIVERSOS FERTILIZANTES NITROGENADOS (*)
}

H. Gargantint e R. A.Catani (**), engenheiros-agrônomos, Seção de Fertilidade do Solo, Instituto Agronômico

\section{R E S U M O}

Neste trabalho sāo apresentados os resultados obtidos em estudos preliminares sôbre a determinação da intensidade e evolução do fenômeno de amonificação e nitrificação em diversos fertilizantes nitrogenađos, empregando-se terra roxa-misturada e os seguintes fertilizantes: sulfato de amônio, uréia, torta de mamona, farinha de sangue, farinha de chifres e cascos e calciocianamida.

Os resultados obtidos permitem concluir que a calciocianamida foi o fertilizante que se amonificou mais intensamente, vindo a seguir a uréia, a torta de mamona, a farinha de sangue e, finalmente, a farinha de chifres e cascos. Já para o fenômeno de nitrificação, os resultados indicam a seguinte ordem decrescente: torta de mamona, uréia, farinha de chifres e cascos, farinha de sanglie e sulfato de amônio. A calciocianamida, dosada no seu teor em nitrogênio nítrico, apresentou sempre traços, mostrando que foi pràticamente nula a sua nitrificação no prazo de $\mathbf{4 0}$ dias de duraçāo do ensaio.

\section{1 - INTRODUÇÃO}

Já é bem conhecido que os vegetais absorvem o nitrogênio, principalmente nas formas nítrica e amoniacal.

Certas plantas cultivadas, como o arroz, preferem, nos primeiros períodos de vida, o nitrogênio na forma amoniacal, enquanto que outras, como a cana-de-açúcar, têm preferência pelo nitrogênio nítrico (9). Outras ainda, como o milho e o algodão, absorvem indiferentemente as duas formas (9). De qualquer maneira. o nitrogênio integrante da matéria orgânica do solo, ou o proveniente da aplicação de fertilizantes que encerrem êsse elemento, em formas diferentes da nítrica e da amoniacal, precisa sofrer, no solo, certas transformações para, então, ser absorvido pelas plantas. Assim, um fertilizante que encerre nitrogênio na forma protêica, amídica ou cianamídica, ao ser colocado no solo

(*) Recebido para publicaçāo em 31 de agôsto de 1957.

(**) Atualmente na Escola Superior de Agricultura “Luiz de Queiroz", en Piracicaba. 
necessita sofrer primeiramente a ação de bactérias amonificadoras ou nitrificadoras, para ser transformado e então poder ser absorvido. $\hat{E}$, portanto, de grande interêsse o conhecimento da natureza e da intensidade da transformação do nitrogênio dêsses fertilizantes quando em contato com o solo, a fim de se avaliar a eficiência dos mesmos.

O objetivo do experimento relatado no presente trabalho foi o de se determinar o período e a intensidade dos fenômenos de amonificação e nitrificação, em diversos fertilizantes nitrogenados, que encerram nitrogênio em formas diferentes da nítrica e da amoniacal.

\section{2 - MATERIAL E METODO}

O tipo de solo empregado nesta experiência foi a terra roxamisturada, da Estação Experimental Central do Instituto Agronômico, em Campinas. A amostra foi tomada a uma profundidade de $0-20 \mathrm{~cm}$, e apresentou as seguintes características:

Argila .......... $35,2 \%$

Limo (areia fina + limo). 40,6\%

Areia grossa ....... 24,2 \%

Umidade equivalente ... 21,3\%

$\mathrm{pH}$ internacional ..... $5, \mathbf{5 , 3 0}$

Carbono (C) ........ 2,06\%

Nitrogênio $(\mathrm{N}) \ldots . . . \quad 0,14 \%$

Fósforo $\mathrm{PO}_{4}^{--}$) (1) . . . 0,13 e. $\mathrm{mg}$ por $100 \mathrm{~g}$ de solo sêco

Potássio $\left(\mathrm{K}^{+}\right)$trocável ... 0,18 e. $\mathrm{mg}$ por $100 \mathrm{~g}$ de solo sêco

Cálcio $\left(\mathrm{Ca}^{++}\right)$trocável . . . 3,63 e. $\mathrm{mg}$ por $100 \mathrm{~g}$ de solo sêco

Magnésio $\left(\mathrm{Mg}^{++}\right)$trocável . 0,07 e. $\mathrm{mg}$ por $100 \mathrm{~g}$ de solo sêco

Os fertilizantes empregados e os respectivos teores em nitrogênio foram: sulfato de amônio, com 20,5\%; uréia, com 46\%; torta de mamona, com 4,5\%; farinha de sangue, com $12 \%$; farinha de chifres e cascos, com $12 \%$ e calciocianamida, com 20,5\%.

Os tratamentos empregados, em três repetições, foram os seguintes:

1 - Testemunha

2 - Sulfato de amônio

3 - Uréia

4 - Torta de mamona

5 - Farinha de sangue

6 - Farinha de chifres e cascos

7 - Calciocianamida.

(1) $\mathrm{PO}_{4}^{--}$fracamente adsorvidn. extraído com solucão de $\mathrm{NH}_{4} \mathrm{E}\left(0,025 \mathrm{~N}\right.$ e $\mathrm{H}_{2} \mathrm{SO}_{4} 0,05 \mathrm{~N}$. 
Foram misturados ìntimamente $400 \mathrm{~g}$ de terra fina (diâmetro menor que $2 \mathrm{~mm}$ ) com $200 \mathrm{mg}$ de nitrogênio na forma dos diversos fertilizantes, em cristalizadores de vidro de $12,5 \mathrm{~cm}$ de diâmetro, e a mistura foi umedecida com água destilada. Como o teor em água que deve ser conservado em um solo para se ter um ótimo de nitrificação é muito variável, segundo Hammence (3), para o presente experimento foi adotado o teor de umidade de $25,6 \%$, ou sejam, $20 \%$ a mais da umidade equivalente.

Êste teor de umidade foi mantido durante todo o experimento, assim como foi assegurada uma temperatura de $30^{\circ} \mathrm{C}$ no decorrer dos 40 dias de duração do ensaio.

Aos dez, vinte, trinta e quarenta dias após a instalação da experiência foram retiradas amostras de terra dos cristalizadores sendo os respectivos teores em nitrogênio amoniacal e riítrico determinados.

O nitrogênio nítrico (nitrato) foi extraído do solo por percolação de $150 \mathrm{ml}$ de solução $0,01 \mathrm{~N}$ de ácido sulfúrico sôbre $50 \mathrm{~g}$ de terra e a determinação, feita pelo método do ácido fenoldissulfônico (10).

O nitrogênio amoniacal foi extraído percolando $100 \mathrm{ml}$ de solução normal de $\mathrm{NaCl}$ sôbre $10 \mathrm{~g}$ de terra, sendo a dosagem conduzida pelo processo de destilação do percolado (6). Uma alíquota foi colocada no aparêlho de destilação, prèviamente preparado conforme Hillebrand e Lundell (4). O destilado foi recolhido em balão calibrado de $100 \mathrm{ml}$, contendo $5 \mathrm{ml}$ de ácido clorídrico $0,1 \mathrm{~N}$. Destilaram-se cêrca de $60 \mathrm{ml}$, que em seguida foram neutralizados com solução de $\mathrm{NaOH}$ 1N. Acrescentou-se água destilada, isenta de amoníaco (8), até aproximadamente $90 \mathrm{ml}$ e a seguir, $2 \mathrm{ml}$ de reativo de Nessler, gôta a gôta, com agitação. Completou-se o volume a $100 \mathrm{ml}$, deixou-se em repouso por 30 minutos e procedeuse à determinação fotométrica em eletrofotômetro de Fisher, filtro 425-B.

\section{3 - RESULTADOS OBTIDOS}

Conforme já foi dito, aos dez, vinte, trinta e quarenta dias após o início da experiência foram retiradas amostras de solo dos cristalizadores, sendo os teores de nitrogênio nítrico e amoniacal dosados. No quadro 1 estão registrados os resultados obtidos nessas dosagens.

Pelos dados obtidos no presente ensaio verifica-se que o sulfato de amônio sofre uma nitrificação contínua e crescente, aumentando muito, porém, a partir do trigésimo dia. Aos dez dias constataram-se apenas traços de nitrato, e aos vinte dias, $0,62 \mathrm{mg}$ de nitrato já se haviam formado. 
를

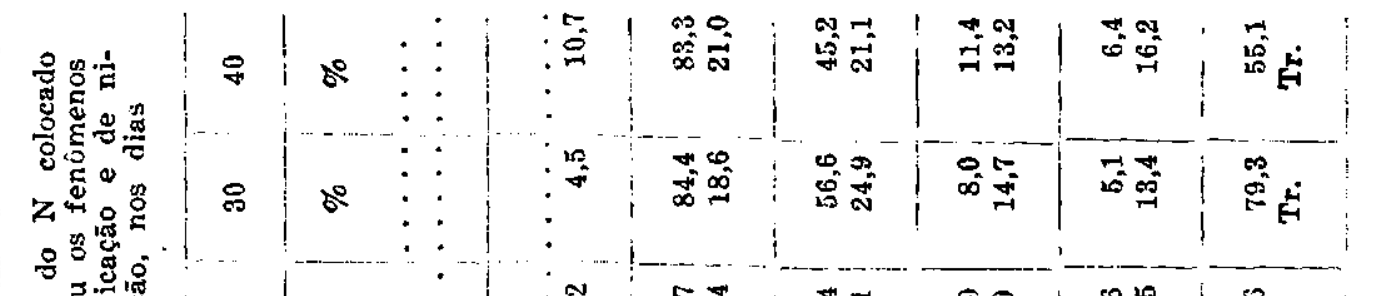
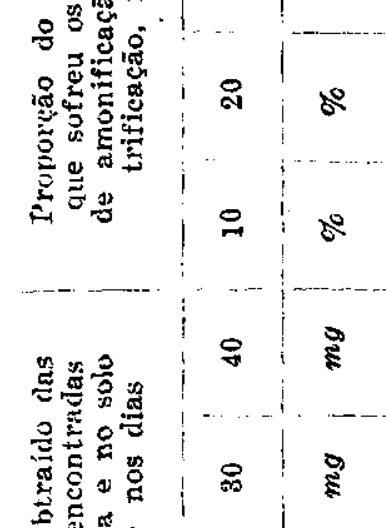

$\stackrel{10}{*}:$

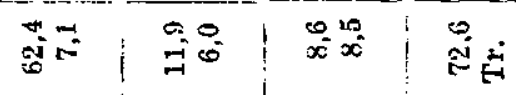

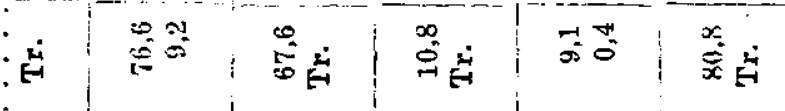

$\circ \quad 2$

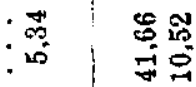

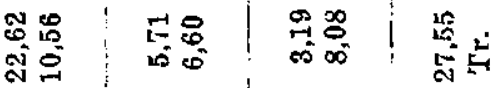

요

-

$8:$ 옹

$:$ :

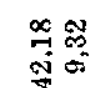

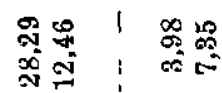

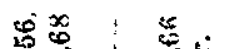

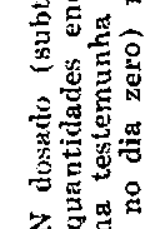

\&

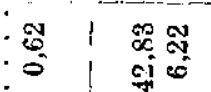

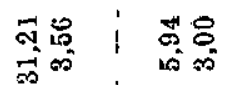

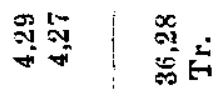

$\because$ ! 열

.

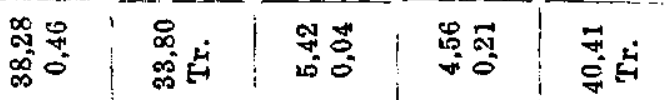

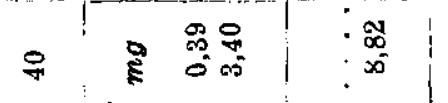

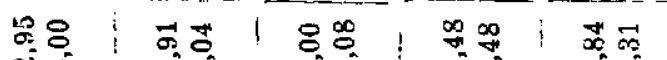

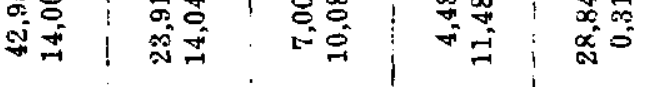

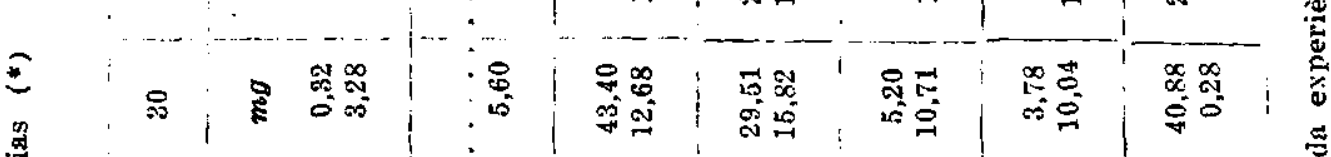

署

丞

:

㺃

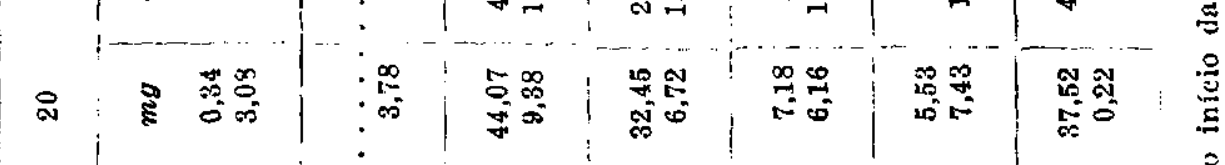

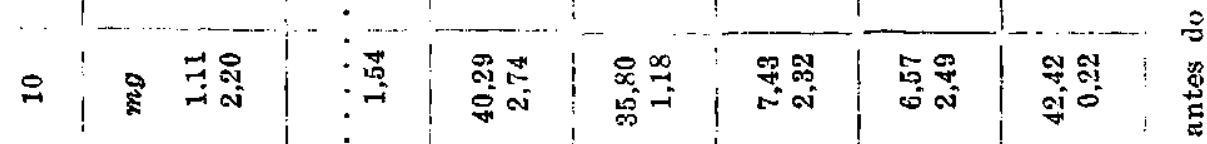

8

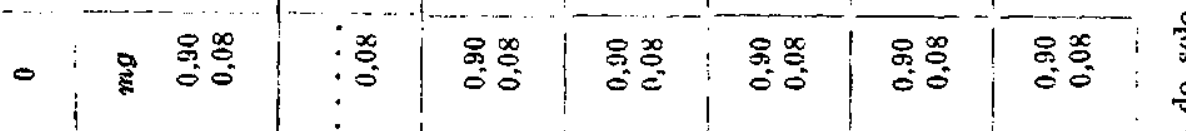

\&్

它

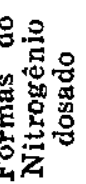

s。

- $\therefore$ : ह 可

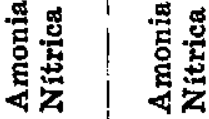


O fertilizante nitrogenado que mais intensamente sofreu o fenômeno de amonificação foi a calciocianamida, pois aos 10 dias cêrca de $80,8 \%$ de seu nitrogênio já passaram à forma amoniacal. Isto indica que o nitrogênio da calciocianamida é intensamente atacado e transformado. Já com o fenômeno de nitrificação, aconteceu exatamente o contrário, isto é, foi pràticamente nula a quantidade de nitrogênio nítrico encontrada, mesmo aos 40 dias. Como já assinalaram alguns autores $(1,2,5$ e 7$)$ êste fato tem origem, provàvelmente, na ação inibidora que os produtos intermediários, formados pela decomposição da calciocianamida, exercem sôbre as bactérias nitrificantes.

As figuras 1 e 2 mostram as curvas porcentuais de nitrificação e amonificação dos diferentes fertilizantes empregados neste experimento. No eixo das abcissas está representado o número de dias de duração do experimento $e$, nas ordenadas, a porcentagem de nitrogênio amonificado e nitrificado.

Pelos resultados obtidos com a uréia verifica-se que, já aos dez dias, êsse fertilizante sofreu intensamente o fenômeno de amonificação, pois cêrca de 38,3 $\mathrm{mg}$, ou sejam $76,6 \%$ de seu nitrogênio, atingiram a forma amoniacal. Aos 20 dias $85,7 \%$ já atingiram aquela forma. Como se pode verificar o fenômeno é bastante intenso neste fertilizante. Os dados são apresentados no quadro 1 e a curva, na figura 1 . Quanto ao fenômeno de nitrificação (figura 2), é também contínuo e rápido, pois em apenas 10 dias $9,2 \%$ do seu nitrogênio já atingiram a forma nítrica, sendo que no final dos 40 dias, cêrca de $21 \%$ do total de seu nitrogênio atingiram aquela forma. Por êsses resultados podemos afirmar que o nitrogênio na forma amídica, que é a forma apresentada pela uréia, é de fácil decomposição.

Quanto à torta de mamona, pôde-se concluir que o seu nitrogênio é de fácil transformação, pois também aos 10

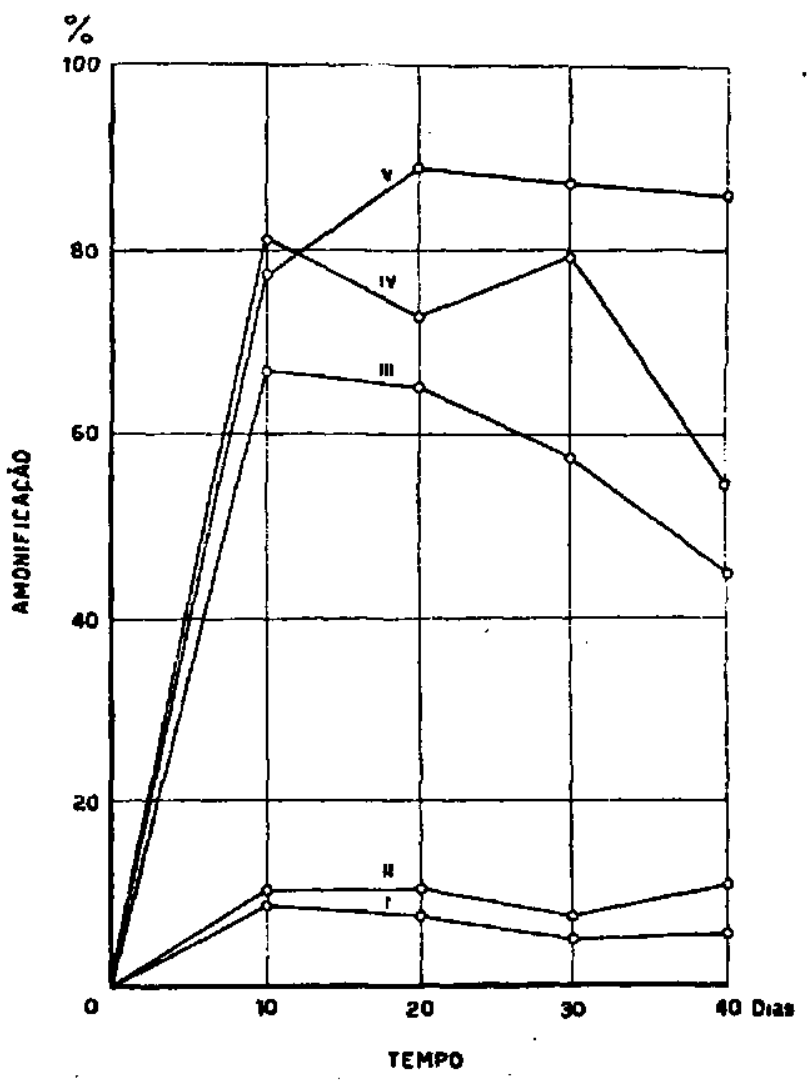

Figura 1. - Fenômeno de amonificação. Curvas traçadas de acôrdo com os teores porcentuais de nitrogênlo amonlacal, dosados aos 10, 20,30 e 40 dias da experiência. Vide explicaçōes da legenda na figura 2. 


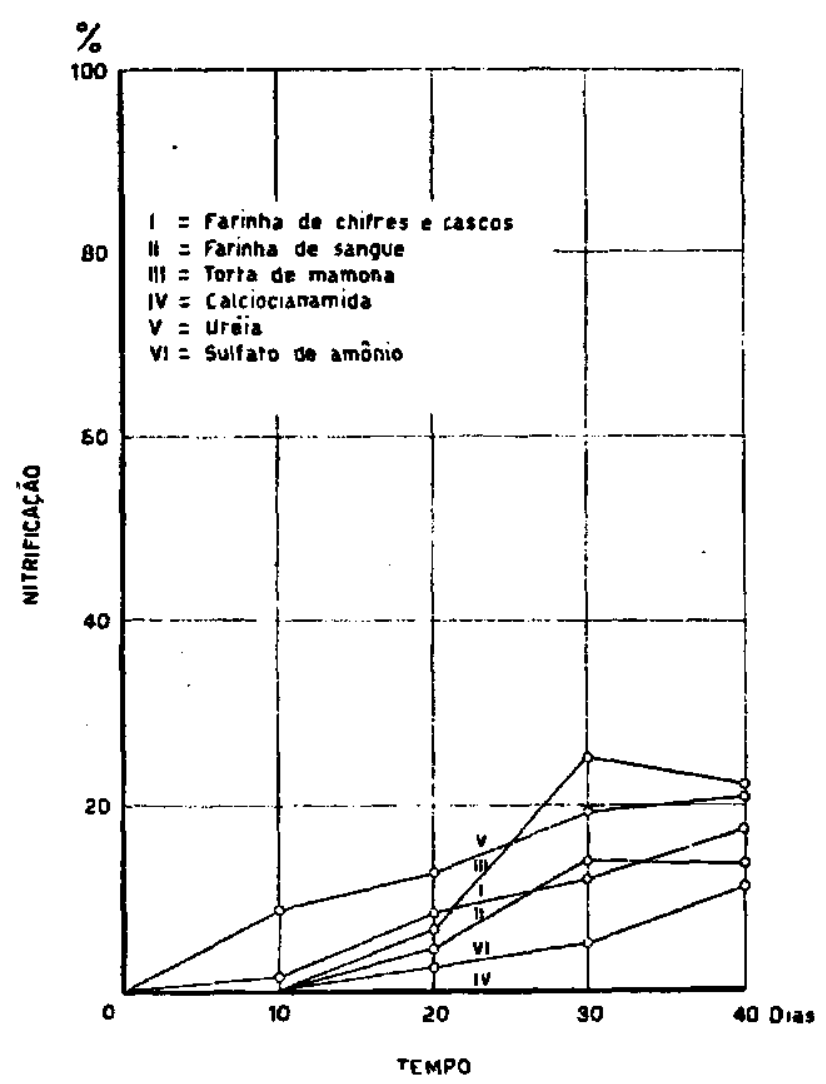

Figura 2. - Fenòmeno de nitrificação. Curvas traçadas de acôrdo com os teores porcentuais de nitrogênio nitrico, dosados aos 10,20,30 e 40 dias da experiência. dias do início da experiência cêrca de $68 \%$ de seu nitrogênio já atingiram a forma amoniacal. O fenômeno de nitrificação neste fertilizante se processa também de modo contínuo e crescente, uma vez que aos 30 dias atingiu a quantidade de $25 \%$ de nitrogênio. Concluímos que o nitrogênio protêico da torta é também fácil e ràpidamente amonificado e nitrificado.

A farinha de sangue se portou de maneira bem inferior aos demais já descritos, porquanto aos 10 dias sòmente $10,8 \%$ de seu nitrogênio tinham sofrido o fenômeno de amonificação. Ao fim dos 40 dias, o total atingido pela amonificação nesse fertilizante foi de $11,4 \%$. O fenômeno de nitrificação é contínuo e crescente, sendo que aos 10 dias atingiu $6 \%$, para alcançar, aos 40 dias, o valor de $13,2 \%$. Como pode ser veri-

ficado, o nitrogênio dêste fertilizante está numa forma mais resistente à decomposição do que os anteriormente descritos.

Finalmente, a farinha de chifres e cascos foi dos fertilizantes estudados o que menor quantidade de nitrogênio amoniacal apresentou. Com referência ao nitrogênio nítrico, a quantidade encontrada foi sempre contínua e crescente, mostrando que a passagem do nitrogênio pela forma amoniacal é bastante rápida, chegando logo à forma nítrica. Ao fim dos 40 dias do experimento, êste fertilizante apresentou $6,4 \%$ de nitrogênio amoniacal e 16,2\% de nitrogênio nítrico, sendo portanto um fertilizante que também se transforma com relativa rapidez.

\section{4 - CONCLUSÕES}

a) Pela velocidade e intensidade do fenômeno de amonificação, os fertilizantes empregados nesta experiência apresentaram-se na seguinte ordem decrescente, dez dias depois de iniciada a experiência: calciocianamida, uréia, torta de mamona, farinha de san- 
gue e farinha de chifres e cascos. Ao fim dos quarenta dias, sòmente houve inversão nos dois primeiros lugares, isto é, a uréia passou a ocupar o primeiro lugar, enquanto a calciocianamida passou para o segundo pôsto.

b) Já com o fenômeno de nitrificação, os fertilizantes comportaram-se diferentemente, pois a ordem decrescente foi a seguinte: aos dez dias de experiência - uréia, farinha de chifres e cascos, torta de mamona, farinha de sangue, sulfato de amônio e, finalmente, a calciocianamida; aos quarenta dias - torta de mamona, uréia, farinha de chifres e cascos, farinha de sangue, sulfato de amônio e, finalmente, a calciocianamida.

c) Pelos resultados obtidos pode ser verificado que, conforme a procedência do nitrogênio amoniacal, êle é ràpidamente, ou não, transformado em nitrogênio nítrico. Assim, por exemplo, o nitrogênio da calciocianamida, que é ràpidamente transformado em nitrogênio amoniacal, não é, entretanto, transformado em nitrogênio nítrico com rapidez, pois que ao fim de 40 dias sòmente traços de nitrogênio nesta forma foram encontrados, enquanto o fenômeno de amonificação neste fertilizante foi bastante intenso.

d) O fertilizante que maior decomposição sofreu foi a uréia, porquanto já aos dez dias apresentou $87,4 \%$ de seu nitrogênio transformados, sendo $76,6 \%$ de forma amoniacal e $10,8 \%$ na forma nítrica.

\section{DETERMINATION OF THE PERIOD OF TIME NEEDED FOR AMMONIFICATION AND NITRIFICATION OF SEVERAL NITROGENOUS FERTILIZERS}

\section{S U M M A R Y}

In this paper results obtained with the phenonenon of ammonification and nitrification in several nitrogen fertilizers are presented. The objective was the determination of the intensity and evolution of these phenomena.

For this purpose an experiment was set up including the following nitrogenous fertilizers: ammonium sulfate, urea, castor bean cake, blood meal, horn and hoof meal and calciumcyanamide.

The experiment was conducted during 40 days; after each ten days period, samples of the different treatments were taken and ammoniacal and nitric nitrogen were determined.

The results obtained show that the calciumcyanamide fertilizer ammonified more intensively, being followed by urea, castor bean cake, blood meal and finally horn and hoof meal. On the other hand concerning the phenomenon of nitrification, the results indicate that the castor bean cake nitrified the most, being followed in descrescent order by urea, horn and hoof meal, blood meal and ammonium sulfate. Results of calciumcyanamide analyses always presented traces of nitric nitrogen, showing that practically no nitrification ocurred during the 40 days of the experiment. 


\section{LITERATURA CITADA}

1. COWIE, G. A. The mechanism of the decomposition of cyanamide in the soil. J. agric. Sci. 10:[163]-176. 1920.

2. CROWTHER, E. M. \& RICHARDSON, H. J. Studies of calcium cyanamide. I - The decomposition of calcium cyanamide in the soil and its effects on germination, nitrification and soil reaction. J. agric. Sci. 22:[300]347. 1932.

3. HAMMENCE, J. H. A method for the determination of relative availability of nitrogen in nitrogenous fertilizers. J. Sci. Fd Agric. 1:92-96. 1950.

4. HILIJEBRAND, W. F. \& LUNDELL, G. E. F. Applied inorganic analysis. New York, John Wiley and Sons, 1929. p. 643.

5. MCCOOL, M. M. Properties and uses of calcium cyanamide. Prof. Pap. Boyce Thompson Inst. 1:226-239. 1933.

6. PRINCE, A. L. Determination of total nitrogen, ammonia, nitrates and nitrites in soils. Soil Sci. 59:[47]-52. 1945.

7. SMOCK, R. M. Some physiological studies with calcium cyanamide and certain of its decomposition products. Wooster, Ohio agric. Exp. Sta., 1953. 46 p. (Bulletin n. 555)

8. SNELL, F. D. \& SNELL, C. T. Colorimetric methods of analysis. New York, D. Van Nostrand Company, Inc., 1936. p. 649.

9. TISDALE, S. L., NELSON, W. L., WELCH, C. D. [e outros]. Sources of nitrogen in crop production. Raleigh, N. C. agric. Exp. Sta., 1952. 63 p. (Technical Bulletin n. 96)

10. VIRDADE, F. C. Dosagem dos nitratos do solo pelo método do ácido fenoldissulfônico. Bragantia 11:[1]-12. 1951. 